\title{
Nursing process for a patient with needle phobia: a case study
}

\author{
Processo de enfermagem para paciente com fobia de agulha: estudo de caso \\ Proceso de enfermería para paciente con fobia a las agujas: estudio de caso
}

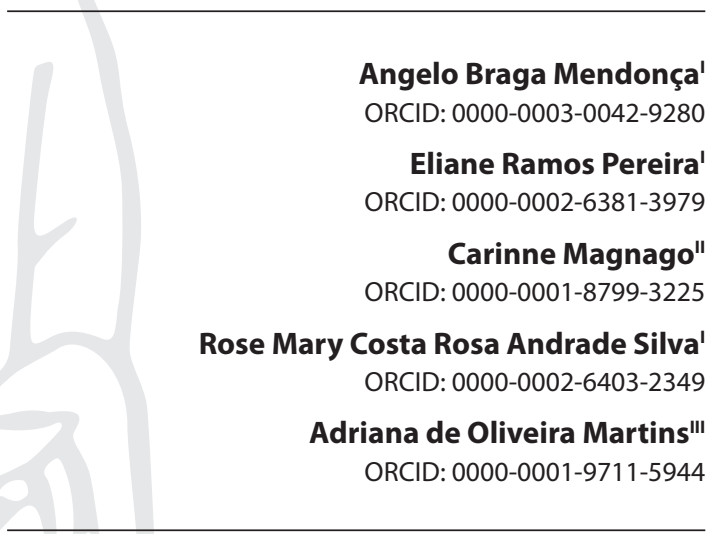

'Universidade Federal Fluminense. Niterói, Rio de Janeiro, Brazil. "Universidade do Estado do Rio de Janeiro. Rio de Janeiro,

Rio de Janeiro, Brazil.

"'Universidade Celso Lisboa. Rio de Janeiro, Rio de Janeiro, Brazil.

How to cite this article: Mendonça AB, Pereira ER, Magnago C, Silva RMCRA, Martins AO. Nursing process for a patient with needle phobia: a case study Rev Bras Enferm. 2020;73(4):e20190095. doi: http://dx.doi.org/10.1590/0034-7167-2019-0095

Corresponding author:

Angelo Braga Mendonça

E-mail: angeloprimax@gmail.com

EDITOR IN CHIEF: Dulce Aparecida Barbosa ASSOCIATE EDITOR: Marcos Brandão

Submission: 02-19-2019

Approval: 10-12-2019

\section{ABSTRACT}

Objectives: to report a clinical case of needle phobia which culminated in cardiac arrest and describe the outcome of a care plan based on fear and anxiety diagnoses, using the Roy adaptation model as the framework. Methods: case study conducted in a chemotherapy outpatient unit in Rio de Janeiro. Care was guided by the nursing process and the use of instruments to assess the venous network, anxiety and fear. Results: the Roy adaptation model enabled proposing nursing interventions that allowed the study subject to adapt to the external and internal stimuli triggered by vasovagal syndrome. The instruments indicated the choice of an adequate semi-implanted venous access device and led to improved levels of anxiety and fear. Final Considerations: after carrying out the nursing activities, anxiety was reduced, and the patient achieved greater control over fear.

Descriptors: Phobic Disorder; Intravenous Infusions; Nursing Care; Catheters; Anxiety

\section{RESUMO}

Objetivos: reportar um caso clínico de fobia de agulha que culminou em parada cardiorrespiratória e descrever os resultados de um plano assistencial voltado aos diagnósticos de medo e ansiedade, tendo como referencial o Modelo de Adaptação de Roy. Métodos: estudo de caso, desenvolvido em ambulatório de quimioterapia do Rio de Janeiro. A atuação profissional foi orientada pelo processo de enfermagem e subsidiada pelo uso de instrumentos de avaliação da rede venosa, ansiedade e medo. Resultados: o Modelo de Adaptação de Roy facultou a proposição de intervenções de enfermagem que permitiram ao sujeito do estudo uma adaptação aos estímulos externos e internos desencadeadores de síndrome vasovagal. Os instrumentos indicaram a escolha de um cateter semi-implantado como dispositivo de acesso venoso adequado que resultou na melhora dos níveis de ansiedade e medo. Considerações Finais: após o desenvolvimento das atividades de enfermagem, a ansiedade diminuiu e o paciente obteve maior autocontrole do medo.

Descritores: Transtornos Fóbicos; Infusões Intravenosas; Assistência de Enfermagem; Cateteres; Ansiedade.

\section{RESUMEN}

Objetivos: informar sobre un caso clínico de fobia a las agujas derivado en paro cardiorrespiratorio, describir los resultados de un plan de atención orientado a diagnósticos de miedo y ansiedad, sobre referencial del Modelo de Adaptación de Roy. Métodos: estudio de caso observado en ambulatorio de quimioterapia de Rio de Janeiro. El trabajo profesional estuvo orientado por el proceso de enfermería, respaldado por utilización de instrumentos evaluadores de la red venosa, ansiedad y miedo. Resultados: el Modelo de Adaptación de Roy ofreció la propuesta de intervenciones de enfermería que le faciliten al sujeto estudiado adaptación a los estímulos externos e internos disparadores del síncope vasovagal. Los instrumentos indicaron que el catéter semiimplantado es el dispositivo de acceso venoso más adecuado, resultando en mejoras de los niveles de ansiedad y miedo. Consideraciones Finales: una vez realizadas las actividades de enfermería, la ansiedad disminuyó y el paciente obtuvo mayor autocontrol del miedo. Descriptores: Trastornos Fóbicos; Infusiones Intravenosas; Atención de Enfermería; Catéteres; Ansiedad. 


\section{INTRODUCTION}

Needle phobia is a term used to describe an anticipatory fear of needle insertion ${ }^{(1)}$. It is a common disorder in children but is often not recognized and treated in adults. Among the invasive procedures performed on cancer patients, venipuncture stands out for its importance and frequency of use. It enables administration of infusions for healing purposes, such as chemotherapy, and support, such as antibiotics, blood components, parenteral fluids and collection of tests ${ }^{(2-3)}$. This procedure, however, despite its numerous benefits, can trigger crises of anxiety, dread and fear in patients, exacerbated by repeated use of the venous network, unsuccessful attempts to puncture, difficult-to-access veins, prolonged use of vesicant or irritant drugs, and other situations that cause stress, such as disease progression and treatment failures ${ }^{(3-4)}$.

In this context, the feeling of fear and anxiety that patients may experience is comprehensible, as normal reactions to a perceived threat. These emotions activate a survival protection response that increases heart and respiratory rates, triggering other physical changes, such as sweating, gastrointestinal discomfort and headaches $^{(3-5)}$. Although fear may be an expected response during venous insertion, provoking symptoms such as fainting, dizziness and blurred vision, high levels of needle phobia can cause serious physiological alterations, resulting in hemodynamic instability ${ }^{(1,4,6)}$.

In the literature, needle phobia has been indicated as the cause of death in well-documented cases, being reported during invasive procedures, such as venipuncture, blood donation, arterial puncture, pleural puncture and intramuscular injections ${ }^{(3)}$. In some cases, the vasovagal response was so severe that it caused an acute myocardial infarction and ischemic stroke. However, even without such extreme consequences, studies have demonstrated that blood pressure can take more than two hours to return to normal and vasovagal response can last up to two days, causing feelings of weakness, fatigue and an even greater desire to avoid needles and painful procedures ${ }^{(6)}$.

Despite the high prevalence in cancer patients undergoing chemotherapy, ranging from $15.7 \%$ to $84 \%$, needle phobia is still underdiagnosed and underreported ${ }^{(3)}$. Since it is a clinical entity that is not known and discussed much in medical and nursing practices, even in specialized events and intravenous therapy literature, needle phobia can be easily confused with other anxiety disorders, such as panic syndrome and generalized anxiety disorder. In this sense, case studies, such as the one presented in this article, can help identify and accurately diagnose this phenomenon, in order to determine adequate interventions during nursing care. As recommended in COFEN Resolution No. $358 / 2009$, the nursing care administered in this study was guided by the nursing process, understood as a methodological instrument that organizes nursing care and imparts quality, structured in five different interrelated and recurrent stages ${ }^{(7)}$.

\section{OBJECTIVES}

To report a clinical case of needle phobia which culminated in cardiac arrest and describe the outcome of a care plan based on fear and anxiety diagnoses, using the Roy adaptation model as the theoretical framework.

\section{METHODS}

\section{Ethical aspects}

Since this study only involved one case, authorization was requested from the institution and patient to publish the data related to the clinical case. After obtaining agreement, the study design was submitted to the Research Ethics Committee of the National Cancer Institute and approved under Opinion No. 2.701.391, of June 8, 2018, in compliance with the ethical precepts set forth in CNS/MS Resolution No. 466/2012. Two copies of the free and informed consent form were signed, by the researcher and participant, after the latter had read and was made aware of the content of the case report.

\section{Type of study}

This is a descriptive study involving a single case, developed in accordance with the guidelines endorsed by the CARE Guidelines, whose goal is to develop, disseminate and implement sufficiently rigorous standards for conducting case studies, informing their results in a transparent manner and guiding clinical practices ${ }^{(8)}$.

\section{Methodological procedures}

This case study describes the nursing care given from March 24 to May 20, 2018 to a patient who went into immediate cardiac arrest after peripheral venous puncture for chemotherapy. The nursing care was guided by the nursing process, as recommended in Resolution 358/2009 of the Federal Nursing Council(7), based on the following guidelines: NANDA International Nursing Diagnoses: Definitions and Classification ${ }^{(9)}$, Nursing Interventions Classification $(\mathrm{NIC})^{(10)}$ and Nursing Outcomes Classification (NOC) ${ }^{(11)}$. The data collection and preliminary clinical judgment were carried out by a nurse with expertise in chemotherapy, nine years of experience in the area, and in the process of doing a professional master's degree. A specialist in cancer nursing and expert in vascular access, with 20 years of experience in intravenous therapy collaborated with the planning and evaluation of the nursing interventions.

\section{Study site}

The study site was an adult chemotherapy outpatient clinic in the city of Rio de Janeiro, RJ, Brazil.

\section{Data collection and organization}

Premised on evidence-based practice (EBP), a search for evidence was conducted in the specialized literature on needle phobia and the practices applicable to nursing diagnoses attributed to the patient in question. The Evidence-Based Portal, Medline and Cochrane Library were searched in March 2018, without a defined time period and language, based on the following terms combined in different strategies: needles, needle phobia, needle fear, anxiety, fear, interventions, hematology, intravenous therapy and venous access devices. During the care process, the following instruments, recommended in the literature, were applied: Beck Anxiety Inventory (BAI), Hospital Anxiety and Depression Scale (HADS), applied before and after the nursing interventions, Venous Assessment Tool 
(VAT) and Deciding on Intravenous Access (DIVA), which guided the decision making regarding which venous device to implant.

The BAl seeks to measure the severity of an individual's anxiety from 21 multiple choice questions that express common symptoms of anxiety. The questionnaire is answered by the individual according to the occurrence of each perceived symptom, where each item must be evaluated on a scale from 0 to 3 points: 0 - Not at all; 1 - Mildly, but it didn't bother me much; 2 - Moderately - it wasn't pleasant at times; and 3-Severely - it bothered me a lot. The sum of the responses indicates minimal anxiety (0-10), mild anxiety (11-19), moderate anxiety (20-30) or severe anxiety (31-63) ${ }^{(12-13)}$. HADS is composed of two subscales: one for anxiety and the other for depression, with seven items each. The overall score in each subscale ranges from 0 to 21 and is used for assessing mild emotional disorders. The interpretation of each subscale is improbable (0-7), possible (8-11) or probable (12-21) ${ }^{(14-15)}$. In this study, only the anxiety subscale was applied.

The VAT is composed of risk factors and characteristics that must be assessed to determine if venous cannulation will be easy, moderate or difficult. A score is assigned to each risk factor: 0 (not present), 1 (present) or 2 (present and will complicate a cannulation attempt), with a subsequent sum that will indicate the action to be taken by the professional: $<3$ (easy) - use routine cannulation; 4-8 (moderate) - consider an alternative access intravenous device for future therapy; $>9$ (difficult) - use an alternative access intravenous device for continuing the therapy. The DIVA instrument, in turn, is an algorithm composed of a series of "yes" or "no" questions which help the professional to decide on the most suitable venous access device for the patient ${ }^{(16)}$.

\section{Data analysis}

The quantitative data in Table 1, obtained from the instruments applied, was quantified and analyzed using descriptive statistics, to assess the results of catheter placement and other nursing interventions. The case and the activities performed during the nursing care were systematized in an orderly and critical report, guided by the stages of the nursing process and compared with the scientific literature on the subject. The Roy adaptation model was used for the theoretical foundation. The theory was chosen because it explains, predicts and assesses behavior resulting from the adaptation process of human beings. It also enables a precise examination of results that emerge from the combination of focal, contextual and residual stimuli ${ }^{(17-18)}$ that people experience in traumatic situations. In this paradigm, two of Roy's theoretical propositions, identified in an integrative literature review of 116 studies, were selected for designing the nursing interventions: the first argues that adaptive responses may be affected by the adjustment of cognitive and regulatory responses; the second, that assessment and nursing interventions are particularly important for managing input (stimuli) and output (responses) in the adaptive system ${ }^{(19)}$.

\section{RESULTS}

\section{Case description}

LS, male, 23 years old, Catholic, obese, brown, single, residing in the city of Rio de Janeiro, with no children, a family history of cancer and a sedentary lifestyle. In February 2018, he was diagnosed with an endodermal sinus tumor coexisting with embryonal carcinoma, high-risk E111b staging, and superior vena cava syndrome (SVCS). At the time, he was admitted for treatment with VIP protocol (Etoposide $75 \mathrm{mg} / \mathrm{m}^{2}$, Ifosfamide $1200 \mathrm{mg} / \mathrm{m}^{2}$ and Cisplatin $20 \mathrm{mg} / \mathrm{m}^{2}$ D1-D5). After completing the first cycle of inpatient chemotherapy, with short-term central venous access in the femoral vein, the patient's response to the protocol was positive, with regression of the SVCS signs and symptoms. He was discharged and referred for ongoing outpatient chemotherapy treatment. In March 2018, on D4 of the second cycle of chemotherapy, during peripheral puncture, the patient fainted and experienced sweating and hypotension. He recovered and the treatment continued without further clinical complications. On D5, he requested that the venous access not be on the dorsum of the hand, since it was extremely uncomfortable. He was pale, sweaty and hypervigilant, with tachy-dyspnea and muscle tension. The vital sign assessment indicated blood pressure of $90 \times 60 \mathrm{mmHg}$, heart and respiratory rate of $98 \mathrm{bpm}$ and $27 \mathrm{rpm}$, respectively, and axillary temperature of $36^{\circ} \mathrm{C}$. During the physical exam, the patient was pale $(1+/ 4+)$, hydrated, acyanotic and anicteric. Pulmonary auscultation showed bilateral breath sounds and no adventitious sounds. Oxygen saturation, measured with a pulse oximeter, was $97 \%$. After attempting to minimize the anxiety and improve the patient's feeling of control over the situation, there was an inspection and palpation of the peripheral venous network. While inserting the catheter (22G), the patient went into cardiac arrest, characterized by loss of consciousness, perioral and extremity cyanosis, dilation of pupils, inaudible blood pressure and non-palpable carotid pulse. He was revived and recovered consciousness after cardiopulmonary resuscitation maneuvers. After his hemodynamic condition stabilized, he received chemotherapy on the scheduled days with no further complications. When questioned about previous needle trauma, he reported having experienced severe discomfort during venous cannulation in the dorsum of the hand to administer contrast. There had been no traumatic events in his childhood and adolescence related to invasive procedures. Since the time of the event considered to be the cause of the phobia, when multiple puncture attempts occurred, he said he has been terrified of intravenous insertions.

\section{Nursing process}

Accompanying the stages of the nursing process, the patient's history was reviewed with an emphasis on assessing possible stimuli originating from an external or internal environment; classified as focal when they are responsible for major changes and decisive impacts on adaptive response; contextual if they stem from other minor situations that have a positive or negative influence on the results of the focal stimuli; and residual, with a role not clearly established or apparent to the individual ${ }^{(18)}$ (Chart 1). A posteriori, it was supplemented with other relevant materials, such as imaging test results, clinical pathology and notes from the multi-professional team, providing input for identification of the following nursing diagnoses on March 24, 2018, based on NANDA ${ }^{(9)}$ : (1) Fear, characterized by signs of agitation, dilated pupils, muscle tension, increased sweating and dyspnea, related to needle phobia and feelings experienced in a previous threat, involving multiple 
venous cannulation attempts with a peripheral catheter; and (2) Anxiety, characterized by hypervigilance, superficial vasoconstriction, dilated pupils, fainting and confusion, related to concerns about further punctures, the future and the threat of death.

Based on these diagnoses, with guidance provided by the EBP, $\mathrm{NIC}$ and theoretical premises from the MAR, the nursing plan was prepared on April 4, 2018 (Chart 2), outlining the interventions that would result in input of new stimuli (placement of the central venous catheter and distraction activities) and output of behavior (patient's control of fear and anxiety) that would prevent further short-term vasovagal syndrome, given the risk of death and abandonment of treatment.

Chart 1 - Focal, contextual and residual stimuli investigated in the nursing record based on Roy adaptation model, Rio de Janeiro, Rio de Janeiro, Brazil, 2018

\begin{tabular}{|l|l|l|}
\hline \multicolumn{1}{|c|}{ Focal } & \multicolumn{1}{|c|}{ Contextual } & \multicolumn{1}{c|}{ Residual } \\
\hline $\begin{array}{l}\text { Exposure to procedures } \\
\text { with needles }\end{array}$ & $\begin{array}{l}\text { Use of tobacco, psychoactive substances, presence of the nurse } \\
\text { and environments that do not offer safety (with smell of antiseptics, } \\
\text { chemotherapy room and laboratory). }\end{array}$ & $\begin{array}{l}\text { Traumatic events in childhood, fear of not } \\
\text { being able to control one's emotions, fear of } \\
\text { not completing the chemotherapy. }\end{array}$ \\
\hline
\end{tabular}

Chart 2 - Nursing interventions and activities, designed on the basis of scientific evidence, for patients with needle phobia, Rio de Janeiro, Rio de Janeiro, Brazil, 2018

\begin{tabular}{|c|c|}
\hline $\begin{array}{l}\text { Nursing } \\
\text { interventions } \\
(\text { NIC) }\end{array}$ & Nursing activities \\
\hline \multirow{4}{*}{$\begin{array}{l}\text { Control of } \\
\text { central venous } \\
\text { access device }\end{array}$} & $\begin{array}{l}\text { Indicate early on a central venous access device, based on individual characteristics and the proposed chemotherapy protocol. } \\
\text { The Adult Venous Assessment Tool (VAT) and Deciding on Intravenous Access (DIVA) were applied for the purpose of decision } \\
\text { making }{ }^{(16)} \text {. }\end{array}$ \\
\hline & Provide information related to the device (type, indication, function and precautions with the device). \\
\hline & Clarify the short-, mid- and long-term risks and benefits of catheters. \\
\hline & Check that the patient understands the purpose, care and maintenance of the semi-implanted catheter. \\
\hline \multirow{8}{*}{$\begin{array}{l}\text { Reduction of } \\
\text { anxiety and fear }\end{array}$} & Help the patient identify situations that precipitate anxiety and fear. \\
\hline & Identify other situations that cause panic and anxiety, such as differential diagnosis ${ }^{(4,20)}$ of needle phobia. \\
\hline & $\begin{array}{l}\text { Apply specific scales for assessing levels of anxiety }{ }^{(10)} \text {, fear and depression, before, during and after chemotherapy. The Beck } \\
\left.\text { Anxiety Inventory }{ }^{(12-13)} \text { and Hospital Anxiety and Depression Scale (anxiety subscale) }\right)^{(14-15)} \text { were applied. }\end{array}$ \\
\hline & $\begin{array}{l}\text { Teach slow breathing exercises to promote relaxation }{ }^{(4)} \text {. Reduction of carbon dioxide blood levels, triggered by hyperventilation, } \\
\text { should be avoided. This results in cerebral vascular constriction, reduced availability of oxygen and syncope symptoms. In } \\
\text { addition, blood pressure levels may also be high due to the intervention }{ }^{(21)} \text {. }\end{array}$ \\
\hline & $\begin{array}{l}\text { Instruct the patient to avoid medications and substances such as alcohol, caffeine and stimulants of the central nervous system, } \\
\text { since they can aggravate the symptoms of anxiety and/or phobia }{ }^{(4)} \text {. }\end{array}$ \\
\hline & $\begin{array}{l}\text { Assess verbal and non-verbal signs of anxiety }{ }^{(10)} \text {, fear and potential psychological complications associated with intravenous } \\
\text { insertion. }\end{array}$ \\
\hline & $\begin{array}{l}\text { Refer to a mental health specialist when necessary, since certain interventions are beyond the technical, ethical and legal } \\
\text { competencies of nurses, in order for the patient to receive psychotherapeutic and clinical treatment for phobia and mood } \\
\text { disorders }{ }^{(4,20)} \text {. }\end{array}$ \\
\hline & $\begin{array}{l}\text { Recognize panic attack risk factors in the nursing record, such as low weight, start of treatment, younger age, fear of fainting, } \\
\text { concerns about health risks, fear of "being afraid", treatment with anxiolytics or antidepressants, smoking and use of illicit } \\
\text { substances }\end{array}$ \\
\hline Counseling & $\begin{array}{l}\text { Educate the patient about the disorder }{ }^{(4,20)} \text {, supplying factual information as necessary and appropriate }{ }^{(10)} \text {. Teach the patient to } \\
\text { replace thoughts that increase fear, such as "expecting to faint" with others that promote self-confidence, such as: "whatever } \\
\text { goes up (fear), comes down". }\end{array}$ \\
\hline Distraction & $\begin{array}{l}\text { Encourage the individual to choose distraction techniques, such as listening to music, deep breathing exercises and recalling } \\
\text { positive events } s^{(4,10,23)} \text {. }\end{array}$ \\
\hline $\begin{array}{l}\text { Promotion } \\
\text { of cerebral } \\
\text { perfusion }\end{array}$ & $\begin{array}{l}\text { Provide instruction in the muscle tension technique, which is the application of repeated isometric tension in the muscles of } \\
\text { the legs, buttocks, abdomen or trunk during other invasive procedures or those with needles. The intervention prevents and } \\
\text { alleviates presyncope and syncope symptoms. This leads to an improvement in cerebral blood flow, oxygenation, cardiac output } \\
\text { and blood pressure. This technique diverts peripheral blood from large muscles to central circulation }{ }^{(21)} \text {. }\end{array}$ \\
\hline
\end{tabular}


As seen in Chart 1, VAT and DIVA were applied on April 4, 2018 for making decisions regarding control of the central venous access device. The results of the VAT (14 points) indicated venous insertion by an expert, requiring an alternative intravenous device for continuation of the therapy; and the DIVA indicated insertion of a tunneled central venous catheter. Considering the patient's characteristics and the specialized literature, the nursing team recommended inserting a long-term, semi-implanted, tunneled central venous catheter in the anterior chest wall. The opinion was submitted to the institution's catheter committee on April 5, 2018, which assessed the justifications, risks and clinical benefits of the device and corroborated with the recommended course of action. Informed consent was obtained from the patient who was then referred to the operating theater to perform the procedure on April 6, 2018. Apart from the activities outlined in Chart 2 , specific scales were applied to evaluate anxiety levels, whose results were tabulated before (April 4, 2018) and after the nursing interventions (May 20,2018). These results are presented in Table 1.

Table 1 - Results of the tools applied for assessing the anxiety levels of the patient before and after the nursing interventions, Rio de Janeiro, Rio de Janeiro, Brazil, 2018

\begin{tabular}{cclcl}
\hline Tool & $\begin{array}{c}\text { Score } \begin{array}{l}\text { Interpretation } \\
\text { Before }\end{array} \\
\begin{array}{c}\text { Beck Anxiety Inventory } \\
\text { (BAl) }\end{array}\end{array} \quad 23 \begin{array}{l}\text { Moderate degree } \\
\text { of anxiety }\end{array}$ & $\begin{array}{c}\text { Score } \\
\text { After }\end{array}$ \\
$\begin{array}{c}\text { Hospital Anxiety and } \\
\text { Depression Scale } \\
\text { (Anxiety subscale) }\end{array}$ & 7 & $\begin{array}{l}\text { Improbable } \\
\text { anxiety profile }\end{array}$ & 4 & $\begin{array}{l}\text { Low degree of } \\
\text { anxiety }\end{array}$ \\
\hline
\end{tabular}

It is worth noting that during the previous application of the tools, the patient demonstrated avoidance in relation to the phobic disorder and denial of the associated symptoms. The evaluation of the effects of the nursing interventions was performed using the indicators established for the results of "self-control of anxiety" and "self-control of fear", as set forth in the NOC (11), on April 4, 2018 and May 20, 2018. Each indicator was assessed on a scale from 1 to 5, where 1 represents less effort in carrying out personal actions to eliminate or reduce feelings related to anxiety and fear. After adding up the points from all the indicators, the overall mean for each nursing outcome was obtained. Before the interventions, the means were 2.1 for self-control of anxiety and 2.4 for self-control of fear. After the interventions, the means rose to 4.1 and 3.6, respectively. This data suggests that case-specific nursing interventions led to effective outcomes for the patient's needs. It should be pointed out that during follow-up, there was a good adaptive response of the patient's cognate and regulatory system to the environment; as the treatment progressed in accordance with the prescribed interventions, there were no detectable adverse events resulting from catheter insertion and the patient was more self-assured.

\section{DISCUSSION}

It is estimated that $10 \%$ to $24 \%$ of the world's population has needle phobia or a high degree of fear of needles ${ }^{(1,24-25)}$, which may be manifested as a powerful or incapacitating disorder. Even after the painful sensation has passed, the emotional sequelae of this phenomenon may remain and, with time, unmitigated pain can increase fear which, in turn, heightens the pain in future procedures, creating a dangerous cycle. In this context, recognizing the psychological sequelae related to needle procedures is important in cancer care and alerts nurses to the fact that uncontrolled pain represents more than just physical suffering ${ }^{(3,6)}$.

Needle phobia disorder, apart from making the venipuncture procedure more difficult, can make it more distressing for patients ${ }^{(16,26)}$. Advanced practice nurses are in a unique position to identify fear and anxiety disorders in cancer patients. They play an important role, since they can recognize the symptoms early on and suspect other causal conditions, such as metastasis in the central nervous system, infection, hypoxia, hypoglycemia, pulmonary embolism during intravenous therapy, use of steroids or antiemetics, alcohol abuse and symptoms of abstinence. In addition, some anxiety disorders can be related to high levels of norepinephrine or serotonin, resulting from reuptake inhibition, obstruction or excess production, requiring specific pharmacological treatment ${ }^{(4)}$. Therefore, the actions they take will depend on their professional skills and technical competencies to recognize such conditions and refer the situation for inter-professional consultation $^{(20)}$.

Nurses can positively influence the quality of life of patients with phobic and anxiety disorders by implementing non-pharmacological interventions, able to minimize the physical and psychological suffering associated with invasive procedures. Achieving a satisfactory outcome, however, requires a careful nursing assessment, since patients with phobia may have vague somatic complaints and, as in the case studied here, do not admit their condition. ${ }^{(4)}$. Roy's theoretical framework makes important contributions in this context, because it understands denial behavior as a coping mechanism of the system, as individuals seek to adapt and maintain their physical integrity. This style of coping can create a desire to reject immunizations, dental treatment and life-saving procedures. Such responses hinder achieving goals in the self-concept and interdependence domains proposed by Roy. From this perspective, a nursing process structured according to the MAR is an important professional tool, since it produces an environment that helps individuals develop a state of "selfawareness" advocated by the theoretician ${ }^{(18)}$. From this perspective, awakening an attitude of awareness basically involves helping the individual to break free from harsh self-criticism and to shift the focus away from reactions to fear, which leads to a ripple effect. However, this does not mean ignoring these aspects, but simply accepting them, understanding internally that these reactions do not represent "the essence of who you are". According to the self-concept adaptive mode, accepting the fear is the first step to being set free from it, whereas denying the experience can turn it into a feeling of self-destructive guilt.

In this study, the EBP-based nursing process permitted developing a care proposal for a patient with needle phobia, whose hemodynamic repercussions culminated in a rare adverse event (cardiac arrest) which put the person's life at risk. Through using the first step of the nursing process - the nursing record - a variety of relevant information was obtained that led to nursing diagnoses congruent with a somatic condition and, consequently, 
to the interventions and outcomes to be evaluated. It is, therefore, an indispensable step for the stages that follow ${ }^{(27)}$, as well as for refuting other diagnoses that may be similar to the clinical presentation. Among the challenges that arise in the clinical judgments of nurses are shared clinical indicators in "Fear" and "Anxiety" diagnoses. Both are inserted within the same area of knowledge (Coping with/Tolerance of Stress domain), with similar attributes from the same class (Coping Response) ${ }^{(9)}$. The accuracy of both diagnoses has been investigated in some studies and point out that fear is the result of a threat identified by the patient. Although this alertness causes an exaggerated autonomic nervous system response in the two diagnoses, culminating in similar clinical changes, the "Anxiety" diagnosis is marked by unspecific fear ${ }^{(28)}$.

In the case analyzed, the subject of the study identifies a specific object of fear, an attribute considered essential for establishing the "Fear" diagnosis. He fears the immediate consequences of needle procedures and experiences a range of physical symptoms, exacerbated by the memory of previous sensations when the needle penetrated the body. The anxiety diagnosis, in turn, likewise accompanied by autonomic reactions, differs in that it is connected to diffuse concerns with imminent danger, part of the experience of having cancer. It was accepted as a second secondary diagnosis based on the state of apprehension noted before chemotherapy sessions. It is also considered in the pathophysiological sphere, that although fear seems to be an amplified component, causing an initial increase in blood pressure and heart rate before venipuncture ${ }^{(6,29)}$, it does not operate independently in phobia. According to various authors, other negative emotions, such as aversion to needles and blood, combined with anxiety, can provoke physiological changes in the autonomic nervous system, leading to a drop in blood pressure, syncope and shock ${ }^{(28)}$, characterizing a biphasic response ${ }^{(29)}$. Therefore, both diagnoses were simultaneously addressed to achieve successful nursing outcomes.

Once the diagnoses were established, the nursing plan was structured, determining the interventions and nursing activities to be implemented, aimed at control of the anxiety and fear by the patient himself and, consequently, prevention of further episodes of needle-related vasovagal syndrome. In this regard, health counseling and education activities were carried out, to increase the patient's knowledge about the causal and control factors during events that trigger fear, stress and/or anxiety and to assure the patient that interventions exist for these conditions ${ }^{(20)}$. Distraction activities were also encouraged, including promotion of relaxation and reduction of anxiety levels before other painful procedures ${ }^{(23,26)}$. In addition, specific scales for assessing anxiety levels (HADS and BAI) were applied in order to identify the preexistence of anxiety and/or fear and increased risk of emergence of psychological complications. They were also used to monitor improvement, deterioration or stabilization of the situation after the nursing interventions.

HADS is one of the most systematically used anxiety measurement tools due to its short length and easiness to complete. However, because of its limitation in relation to cutoff point variability and since it is less recommended for cancer patients ${ }^{(30)}$, $\mathrm{BAI}$, considered the gold standard for measuring anxiety, was also used, especially because of its simplicity, apparent ability to measure overall anxiety and quickness for measuring anxiety, with a focus on somatic symptoms ${ }^{(12,31)}$. After the interventions to alleviate anxiety and fear, it was necessary to assess and select the catheter to be used, taking into account age, lifestyle and the patient's preference and agreement. A detailed analysis should also identify the diagnosis, treatment plan, type of prescribed therapy and its duration, ability for self-care, device maintenance resources and psychological aspects, such as high levels of needle phobia and fear ${ }^{(26,32)}$.

In this context, the use of tools to assess the venous network and access helps make safer and correct choices regarding the best vascular access ${ }^{(16)}$. In this study, VAT and DIVA were used, whose results suggested insertion of a long-term, semi-implanted, tunneled central venous catheter. This recommendation was substantiated by the literature, which indicates the use of fully implanted catheters and peripherally inserted central catheters in chemotherapy protocols that include drugs and parenteral solutions with $\mathrm{pH}$ extremes and serum osmolarity, but argues against such use when a high flow of venous hydration is required. In addition, vesicant or irritant drugs administered to peripheral veins may cause them to become sclerosed or damaged over time and may increase the risk of leakage and infiltration. The use of central venous catheters, in such circumstances, can reduce this risk ${ }^{(33)}$. Long-term, semi-implanted, tunneled central venous catheters dispense with percutaneous puncture. The team considered it the most appropriate option since it would provoke less physical trauma and psychological morbidity and prevents the serious consequences of further vasovagal syndrome in the subject of the study. Furthermore, according to the literature, tunneled catheters have many advantages for the case in question. Apart from longer catheter duration and attachment, they offer less risk of infection, since the subcutaneous tunnel and Dacron cuff reduce the entry of microorganisms to the blood stream, ensuring adherence to scar tissue by forming an internal anchor. As for disadvantages, mechanical complications have been mentioned, such as fracture of the catheter, incorrect positioning and obstructions by thrombi ${ }^{(34)}$.

DIVA is an instrument specially designed to assess difficulty of insertion of intravenous lines in cancer patients receiving chemotherapy. Its initial results indicate that is an easy and highly reliable tool, taking only a few minutes to complete. It may be particularly useful for novice nurses, by enabling immediate identification of patients with peripheral access difficulty, as well as candidates for central catheters. The case report of the present study corroborates another validation study of this tool, demonstrating its practical usefulness. Therefore, central vascular access can be immediately recommended in the nursing assessment for patients at greater risk of venous complications and access difficulty, thereby avoiding repeated puncture attempts and impairment of the peripheral venous access ${ }^{(33)}$.

VAT, in turn, determines the level of cannulation difficulty through an analysis of the peripheral venous network and, then, recommends possible devices based on this diagnosis. From this perspective, the combined application of VAT and DIVA enables standardization of nursing judgments and identification of patients that may benefit from alternative venous devices at the start of the planning process, enabling greater comfort and reduced pain, 
anxiety and distress. This indication ensures that the treatment will be safely and efficiently administered ${ }^{(16)}$.

\section{Limitations of the study}

The main limitation of this study is the fact that it was not possible to evaluate and explore other modes of adaptation suggested by Roy, such as role function in social relationships, due to the number of cycles that were missing to complete the proposed treatment.

\section{Contributions to the field of nursing, health or public policy}

The present report adds scientific knowledge to clinical reasoning in nursing, providing input for further studies that seek to identify specific clinical indicators that are able to distinguish conceptual nuclei from diagnoses under analysis. The sharing of defining characteristics and the possibility of clinical co-existence may lead to wrong interpretations that underestimate the prevalence and morbidity of the diagnosis of fear to the detriment of anxiety during chemotherapy. It is expected, therefore, that establishing more accurate diagnostic criteria, which are strong in terms of sensitivity, specificity and positive predictive value, may promote nursing interventions capable of reducing the risk of complications associated with a state of physiological arousal caused by needle panic. It also demonstrates the beneficial results of implanting catheters that dispense with percutaneous puncture in patients with needle phobia, which could be studied in future clinical trials. Within the cancer context, this article alerts nurses to the potential risks and of intravenous puncture in patients with phobia. It highlights a rare event with a significant impact on nursing practices and encourages the reporting of cases with classic and unusual presentations of needle phobia that constitute a challenge to teams.

\section{CONCLUSIONS}

Due to being associated with physical and psychological complications, venous puncture in patients undergoing antineoplastic chemotherapy becomes a complex procedure that should be performed by trained nurses, to ensure that this intervention occurs safely and competently, with a minimum of trauma. In this context, the MAR-based nursing process was an important methodological tool since it favors clinical judgment of nonadaptive responses, identifying fear and anxiety - triggered by the presence of a needle or anticipated exposure to one - as priority diagnoses and consequently promoted effective nursing care aimed at controlling the focal stimuli that placed the patient's life at risk. The data collection, assisted by the use of tools for assessing anxiety levels and the venous network, guided the decision making of the nurse to indicate a long-term, semi-implanted, tunneled central venous catheter, as well as prescribe non-pharmacological nursing interventions that would reduce other contextual and residual stimuli. It was found that, after carrying out the prescribed activities and placing a long-term, semi-implanted, tunneled central venous catheter, anxiety levels dropped and the patient improved in terms of being able to control episodes of fear and anxiety, demonstrating good adaptation in the physical, physiological and self-concept domains proposed by Roy.

\section{REFERENCES}

1. Cook LS. Needle phobia. J Infus Nurs. 2016;39(5):273-9. doi: 10.1097/NAN.0000000000000184

2. Gorski L, Hadaway L, Hagle ME, McGoldrick M, Orr M, Doellman D. Infusion therapy: standards of practice. J Infus Nurs. 2016;39(1S):S1-159. doi: $10.1097 / \mathrm{NHH} .0000000000000481$

3. McLenon J, Rogers MAM. The fear of needles: a systematic review and meta-analysis. J Adv Nurs. 2019;75(1):30-42. doi: 10.1111/jan.13818

4. Marrs JA. Stress, fears, and phobias: the impact of anxiety. Clin J Oncol Nursing. 2006;10(3):319-22. doi: 10.1188/06.CJON.319-322

5. Firmeza M, Rodrigues A, Melo G, Aguiar M, Cunha G, Oliveira P, et al. Control of anxiety through music in a head and neckoutpatient clinic: a randomized clinical trial. Rev Esc Enferm USP. 2017;51:e03201. doi: 10.1590/s1980- 220×2016030503201

6. Jenkins K. Needle phobia: a psychological perspective. Br J Anaesth. 2014;113(1):4- 6. doi: 10.1093/bja/aeu013

7. Conselho Federal de Enfermagem. Resolução COFEN 358/2009. Dispõe sobre a Sistematização da Assistência de Enfermagem e a implementação do Processo de Enfermagem em ambientes, públicos ou privados, em que ocorre o cuidado profissional de Enfermagem, e dá outras providências. Brasília, DF: COFEN; 2009.

8. Gagnier JJ, Kienle G, Altman DG, Moher D, Sox H, Rileynd D, CARE Group. The CARE guidelines: consensus-based clinical case reporting guideline development. Glob Adv Health Med. 2013;2(5):38-43. doi: 10.7453/gahmj.2013.008

9. NANDA Internacional. Diagnósticos de enfermagem da NANDA-I: definições e classificação 2018-2020. 11a ed. Porto Alegre: Artmed; 2018.

10. Bulechek GM, Butcher HK, Dochterman JM, Wagner CM. NIC - Classificação das intervenções de enfermagem. $6^{a}$ ed. Rio de Janeiro: Elsevier; 2016.

11. Moorhead S, Johnson M, Maas ML, Swanson E. NOC - Classificação dos Resultados de Enfermagem: mensuração dos resultados em saúde. $5^{\text {a }}$ ed. Rio de Janeiro: Elsevier; 2016.

12. Beck AT, Epstein N, Brown G, Steer RA. An inventory for measuring clinical anxiety: psychometric properties. J Consult Clin Psychol. 1988;56(6):893-7. doi: 10.1037/0022-006X.56.6.893 
13. Cunha JA. Manual da versão em português das Escalas Beck. São Paulo: Casa do Psicólogo; 2001.

14. Zigmond AS, Snaith RP. The hospital anxiety and depression scale. Acta Psychiatr Scand. 1983;67(6):361-70. doi: 10.1111/j.1600-0447.1983. tb09716.x

15. Botega NJ, Bio MR, Zomignani MA, Garcia Jr C, Pereira WAB. Transtornos do humor em enfermaria de clínica médica e validação de escala de medida (HAD) de ansiedade e depressão. Rev Saúde Pública. 1995;29(5):355-63. doi: 10.1590/S0034-89101995000500004

16. Wells S. Venous access in oncology and haematology patients: part two. Nurs Stand. 2008;23(1):35-42. doi: 10.7748/ns2008.09.23.1.35.c6652

17. Freitas MC, Guedes MVC, Galiza FT, Nogueira JM, Onofre MR. Elderly residents in homes for the aged: adjustment in the light of Callista Roy. Rev Bras Enferm. 2014;67(6):905-12. doi: 10.1590/0034-7167.2014670607

18. Medeiros LP, Souza MBC, Sena JF, Melo MDM, Costa JWS, Costa IKF. Modelo de adaptação de Roy: revisão integrativa de estudos realizados à luz da teoria. Rev Rene. 2015;16(1):132-40. doi: 10.15253/2175-6783.2015000100017

19. Frederickson K. Nursing knowledge development through research: using the Roy adaptation model. Nurs Sci Q. 2000;13(1):12-6. doi: $10.1177 / 089431840001300105$

20. McGrandles A, Duffy T. Assessment and treatment of patients with anxiety. Nurs Stand. 2012;26(35):48-57. doi: http://dx.doi.org/10.7748/ ns2012.05.26.35.48.c9082

21. Kowalsky JM, Conatser R, Ritz T, France CR. Effects of respiratory and applied muscle tensing interventions on responses to a simulated blood draw among individuals with high needle fear. J Behav Med. 2018;41(6):771-83. doi: 10.1007/s10865-018-9925-8

22. Miedziun P, Czabała JC. Stress Management Techniques. Arch Psychiatry Psychother. 2015;17(4):23-31. doi: 10.12740/APP/61082

23. Sampaio F, Sequeira C, Canut MTL. Intervenções psicoterapêuticas de enfermagem NIC na prática clínica em Portugal: um estudo descritivo. Rev Port Enferm Saúde Mental. 2016;16:11-8. doi: 10.19131/rpesm.0152

24. Taddio A, Ipp M, Thivakaran S, Jamal A, Parikh C, Smart S, et al. Survey of the prevalence of immunization non-compliance due to needle fears in children and adults. Vaccine. 2012;30(32):4807-12. doi: 10.1016/j.vaccine.2012.05.011

25. McMurtry CM, Noel M, Taddio A, Antony MM, Asmundson GJ, Riddell RP et al, HELP in Kids \& Adults Team. Interventions for individuals with high levels of needle fear: systematic review of randomized controlled trials and quasi-randomized controlled trials. Clinical $J$ Pain. 2015;31(10 Suppl):S109-23. doi: 10.1097/AJP.0000000000000273

26. McGowan D. Peripheral intravenous cannulation: managing distress and anxiety. Br J Nurs. 2014;23(Supp 19):S4-9. doi: 10.12968/ bjon.2014.23.Sup19.S4

27. Coelho AV, Molina RM, Labegalini MPC, Ichisato SMT, Pupulim JSL. Validation of a nursing report for a pediatric intensive care unit. Rev Gaúcha Enferm. 2017;38(3):e68133. doi: 10.1590/1983-1447.2017.03.68133

28. Bergamasso EC, Rossi LA, EC Carvalho, MCB Dalri. Diagnósticos de medo e ansiedade: validação de conteúdo para o paciente queimado. Rev Bras Enferm. 2004;57(2):170-7. doi: 10.1590/S0034-71672004000200008

29. Olatungi BO, Connolli KM, David B. Behavioral avoidance and self-reported fainting symptoms in blood/injury fearful individuals: an experimental test of disgust domain specificity. Journal of Anxiety Disorders. 2008; 20:837-48. doi: 10.1016/j.janxdis.2007.08.010

30. Wakefield CE, Butow PN, Aaronson NA, Hack TF, Hulbert-Williams NJ, Jacobsen PB. International Psycho-Oncology Society Research Committee. Patient-reported depression measures in cancer: a meta-review. Lancet Psychiatry. 2015;2(7):635-47. doi: 10.1016/ S2215-0366(15)00168-6

31. Lemos MF, Lemos-Neto SV, Barrucand L, Verçosa N, Tibirica E. Preoperative education reduces preoperative anxiety in cancer patients undergoing surgery: usefulness of the self-reported Beck anxiety inventory. Rev Bras Anestesiol. 2018;2019;69(1):1-6. doi: 10.1016/j. bjan.2018.07.003

32. Pagnutti L, Bin A, Donato R, Di Lena G, Fabbro C, Fornasiero L, et al. Difficult intravenous access tool in patients receiving peripheral chemotherapy: a pilot validation study. Eur J Oncol Nurs. 2015;20:58-63. doi: 10.1016/j.ejon.2015.06.008

33. Coyle CE, Griffie J, Czaplewski LM. Eliminating extravasation events: a multidisciplinary approach. J Infus Nurs. 2015;38(3):S43-50. doi: 10.1097/NAN.0000000000000034 29

34. Zerati AE, Wolosker N, Luccia N, Puech-Leão P. Totally implantable venous catheters: history, implantation technique and complications. J Vasc Bras. 2017;16(2):128-39. doi: 10.1590/1677- 10.1590/1677-5449.008216 